ARTICLE

Received 21 Sep 2014 | Accepted 28 Nov 2014 | Published 14 Jan 2015

DOI: $10.1038 /$ ncomms6982

OPEN

\title{
An efficient molybdenum disulfide/cobalt diselenide hybrid catalyst for electrochemical hydrogen generation
}

Min-Rui Gao ${ }^{1, \star}$, Jin-Xia Liang ${ }^{2,3, \star}$, Ya-Rong Zheng ${ }^{1}$, Yun-Fei X ${ }^{1}$, Jun Jiang ${ }^{1}$, Qiang Gao ${ }^{1}$, Jun Li $^{2} \&$ Shu-Hong Yu ${ }^{1}$

The electroreduction of water for sustainable hydrogen production is a critical component of several developing clean-energy technologies, such as water splitting and fuel cells. However, finding a cheap and efficient alternative catalyst to replace currently used platinum-based catalysts is still a prerequisite for the commercialization of these technologies. Here we report a robust and highly active catalyst for hydrogen evolution reaction that is constructed by in situ growth of molybdenum disulfide on the surface of cobalt diselenide. In acidic media, the molybdenum disulfide/cobalt diselenide catalyst exhibits fast hydrogen evolution kinetics with onset potential of $-11 \mathrm{mV}$ and Tafel slope of $36 \mathrm{mV}$ per decade, which is the best among the non-noble metal hydrogen evolution catalysts and even approaches to the commercial platinum/carbon catalyst. The high hydrogen evolution activity of molybdenum disulfide/ cobalt diselenide hybrid is likely due to the electrocatalytic synergistic effects between hydrogen evolution-active molybdenum disulfide and cobalt diselenide materials and the much increased catalytic sites.

\footnotetext{
${ }^{1}$ Division of Nanomaterials \& Chemistry, Hefei National Laboratory for Physical Sciences at Microscale, Collaborative Innovation Center of Suzhou Nano Science and Technology, Department of Chemistry, University of Science and Technology of China, Hefei 230026, China. ${ }^{2}$ Key Laboratory of Organic Optoelectronics and Molecular Engineering of Ministry of Education, Department of Chemistry, Tsinghua University, Beijing 100084, China. ${ }^{3}$ Guizhou Provincial Key Laboratory of Computational Nano-Material Science, Guizhou Normal College, Guiyang 550018, China. * These authors contributed equally to this work. Correspondence and requests for materials should be addressed to S.-H.Y. (email: shyu@ustc.edu.cn).
} 
O wing to their diffuse nature, electricity from renewable but intermittent energy (for example, solar and wind) must be stored durably for off-grid applications. Electrochemical water splitting to produce hydrogen $\left(\mathrm{H}_{2}\right)$ offers a promising and sustainable solution for this purpose by converting such electricity energy into stable chemical bonds ${ }^{1,2}$. Appropriate electrocatalysts, such as platinum $(\mathrm{Pt})$ and its alloys, play a vital role in the $\mathrm{H}_{2}$ evolution reaction (HER) because they can catalyse the conversion from a pair of protons and electrons to $\mathrm{H}_{2}$ at high reaction rates and low overpotentials $(\eta)^{1-3}$. However, the prohibitive cost and scarcity of Pt pose tremendous limitations to widespread use. Therefore, finding robust and efficient alternative catalysts that are geologically abundant is crucial to the future of 'hydrogen economy'.

Molybdenum disulfide $\left(\mathrm{MoS}_{2}\right)$, a widely used industrial catalyst for hydrodesulfurization ${ }^{4}$, has recently demonstrated promise as effective HER catalyst based on both computational and experimental studies ${ }^{5,6}$. The HER activity was discovered to arise from the exposed (10-10) planes on edges of $\mathrm{MoS}_{2}$, whereas the $(0001)$ basal planes are catalytically inactive ${ }^{5-7}$. This understanding has led to great efforts to develop highly nanostructured $\mathrm{MoS}_{2}$-based HER catalysts to maximize the number of edge sites, including crystalline $e^{8-12}$ and amorphous materials ${ }^{13-15}, \mathrm{MoS}_{2}$-based hybrid materials ${ }^{16-19}$ and molecular mimics ${ }^{7}$. Despite significant success, the design and fabrication of $\mathrm{MoS}_{2}$-based HER electrocatalysts with satisfactory activity and stability remain a big challenge.

In recent years, we have been making efforts to explore efficient electrocatalysts by using Earth-abundant $3 d$ metal (Co, Ni and so on) chalcogenides ${ }^{20-27}$. New NiSe nanofibres ${ }^{24}$ and lamellar mesostructured $\mathrm{CoSe}_{2} / \mathrm{DETA}$ (DETA, diethylenetriamine) nanobelts ${ }^{25}$ were found to show decent HER activity in acidic electrolyte. Kong et al. ${ }^{28}$ also observed good HER activities from various polycrystalline transition metal dichalcogenide $\left(\mathrm{ME}_{2}, \mathrm{M}=\mathrm{Fe}, \mathrm{Co}, \mathrm{Ni} ; \mathrm{E}=\mathrm{S}, \mathrm{Se}\right)$ films, especially from the $\mathrm{CoSe}_{2}$. Recently, we found that the HER activity of $\mathrm{CoSe}_{2}$ nanobelts can be improved greatly after anchoring $\mathrm{Ni} / \mathrm{NiO}$ nanoparticles onto their surfaces ${ }^{25}$. The synergetic chemical coupling effects between $\mathrm{CoSe}_{2}$ and grafted $\mathrm{Ni} / \mathrm{NiO}$ were believed to contribute to the enhancement. Similar promoted performances have also been observed on $\mathrm{MoS}_{2}$ /graphene ${ }^{16,17}$, $\mathrm{MoO}_{3} / \mathrm{MoS}_{2}$ (ref. 18) and $\mathrm{MoS}_{2} / \mathrm{Au}$ (ref. 19) composite catalysts for $\mathrm{H}_{2}$ production. These works point to the possibility to access new and efficient HER catalysts by combining the promising $\mathrm{CoSe}_{2}$ and $\mathrm{MoS}_{2}$.

We report here that a HER electrocatalyst based on quasi-amorphous $\mathrm{MoS}_{2}$-coated $\mathrm{CoSe}_{2}$ (denoted as $\mathrm{MoS}_{2} / \mathrm{CoSe}_{2}$ ) hybrid is highly active and stable in acidic electrolyte. Notably, without any noble metals, the $\mathrm{MoS}_{2} / \mathrm{CoSe}_{2}$ hybrid catalyst shows an onset potential close to commercial Pt catalyst (JohnsonMatthey, $20 \mathrm{wt} \% \mathrm{Pt} / \mathrm{XC}-72$ ) and a small Tafel slope of $\sim 36 \mathrm{mV}$ per decade as well as no current loss after long-term chronoamperometry measurement, performing the best among the noble-metal-free HER electrocatalysts. These results suggest a strategy for designing non-noble metal catalysts with enhanced HER performance that is comparable to the state-of-the-art Ptbased catalysts.

\section{Results}

$\mathrm{MoS}_{2} / \mathrm{CoSe}_{2}$ hybrid catalyst. The $\mathrm{MoS}_{2} / \mathrm{CoSe}_{2}$ hybrid was prepared directly in a closed $\mathrm{N}, \mathrm{N}$-dimethylformamide (DMF)/ hydrazine solvothermal system, where $\left(\mathrm{NH}_{4}\right)_{2} \mathrm{MoS}_{4}$ was used as a precursor for growing $\mathrm{MoS}_{2}$ around the freshly made $\mathrm{CoSe}_{2} /$ DETA nanobelt substrates (Fig. 1a; Supplementary Fig. 1; see Methods for details of the synthesis). The $\mathrm{MoS}_{2}$-coated $\mathrm{CoSe}_{2}$ hybrid was shown by means of scanning electron microscopy and transmission electron microscopy (TEM; Fig. 2a-c), which revealed the compact graphene-like $\mathrm{MoS}_{2}$ nanosheets grown on the surface of $\mathrm{CoSe}_{2}$ with a partially free-standing branch-like feature (Supplementary Fig. 2). Substantial amino groups on the $\mathrm{CoSe}_{2} /$ DETA surface (Supplementary Fig. 3) serve as nucleation sites for coupling Mo precursor and subsequently reduced to $\mathrm{MoS}_{2}$ on $\mathrm{CoSe}_{2}$ (refs 21,23). A control experiment performed under identical synthesis conditions, but without $\mathrm{CoSe}_{2}$ nanobelts, produced three-dimensional (3D) aggregates of $\mathrm{MoS}_{2}$ sheets (Fig. 1b; Supplementary Fig. 4), suggesting that $\mathrm{CoSe}_{2}$ could be a useful support for mediating the growth of loaded materials and constructing novel functional hybrids.

Figure $2 \mathrm{~d}$ presents high-resolution TEM (HRTEM) images of the $\mathrm{MoS}_{2} / \mathrm{CoSe}_{2}$ hybrid. Layered $\mathrm{MoS}_{2}$ (often less than five layers) nanosheets, with an interlayer separation of $0.63 \mathrm{~nm}$, were grown intimately on the $\mathrm{CoSe}_{2}$ substrate. High-crystalline $\mathrm{CoSe}_{2}$ substrate with $d$ spacing of $0.27 \mathrm{~nm}$ can be seen frequently through the interspace of grafted $\mathrm{MoS}_{2}$ (see Supplementary Fig. 5 for additional images). This non-fully covered structure may take advantage of merits from both $\mathrm{MoS}_{2}$ and $\mathrm{CoSe}_{2}$ for catalysing $\mathrm{H}_{2}$ evolution. Selected area electron diffraction (SAED) pattern (inset in Fig. 2c; Supplementary Fig. 6) revealed clear diffraction spots (marked by yellow arrows) from single-crystalline $\mathrm{CoSe}_{2}$ support (JCPDS 9-0234) and also faint diffraction rings from grafted $\mathrm{MoS}_{2}$ (JCPDS 77-1716). These barely recognizable diffraction rings indicate the quasi-amorphous structure of $\mathrm{MoS}_{2}$, consistent with the X-ray diffraction (XRD) data of $\mathrm{MoS}_{2} / \mathrm{CoSe}_{2}$ with broadening diffraction peaks (Fig. 2e). Inasmuch as amorphous $\mathrm{MoS}_{2}$ has recently been demonstrated to be effective HER catalysts $^{13-15}$ for its abundant defects and resultant more active edge sites $^{29}$, we thus infer that the quasi-amorphous $\mathrm{MoS}_{2}$ modification may benefit the hybrid material to catalytically evolve $\mathrm{H}_{2}$. Energy-dispersive X-ray spectrum (EDX; Fig. 2f) analysis further confirmed the formation of $\mathrm{MoS}_{2} / \mathrm{CoSe}_{2}$ hybrid with $\mathrm{Co}, \mathrm{Se}, \mathrm{Mo}$ and $\mathrm{S}$ as the principal elemental components $(\mathrm{Cu}$ and $\mathrm{C}$ peaks emanate from the carbon-coated TEM grid), agreeing with the X-ray photoelectron spectroscopy (XPS) results (Supplementary Fig. 7). Scanning TEM (STEM) and EDX elemental mappings revealed uniform spatial distribution of Co, $\mathrm{Se}, \mathrm{Mo}$ and $\mathrm{S}$ over the marked detection range of the constructed hybrid material (Fig. 2g).

Catalytic hydrogen evolution. To assess the HER electrocatalytic activity, thin film of various catalysts was prepared on glassy carbon (GC) electrodes for cyclic voltammetry in $\mathrm{H}_{2}$-saturated $0.5 \mathrm{M} \mathrm{H}_{2} \mathrm{SO}_{4}$ electrolyte (see Methods for experimental details). Potentials were measured vs saturated calomel electrode (SCE) and are reported vs reversible hydrogen electrode (RHE). The electrode was kept rotating (1,600 r.p.m.) during the measurements to remove in situ-emerged $\mathrm{H}_{2}$ bubbles. Figure $3 \mathrm{a}$ shows that GC electrode guarantees a minimal background activity for $\mathrm{H}_{2}$ evolution. A reductive sweep of $\mathrm{MoS}_{2} / \mathrm{CoSe}_{2}$ hybrid showed a low $\eta$ of $11 \mathrm{mV}$ for the HER, beyond which a sharp increase in cathodic current was observed, corresponding to catalytic $\mathrm{H}_{2}$ evolution (Fig. 3a; Supplementary Fig. 9). By contrast, pure $\mathrm{CoSe}_{2}$ nanobelts exhibited inferior HER activity with a larger onset potential of $\sim 50 \mathrm{mV}$ and lower catalytic current, while pure $\mathrm{MoS}_{2}$ nanosheet aggregates only affected little HER activity. The HER kinetics of the above catalysts was probed by corresponding Tafel plots $(\log j \sim \eta)$ (Fig. 3b). Tafel slope of $\sim 36 \mathrm{mV}$ per decade was measured for $\mathrm{MoS}_{2} / \mathrm{CoSe}_{2}$ hybrid, which is close to the value of $30 \mathrm{mV}$ per decade for $\mathrm{Pt} / \mathrm{C}$ catalyst and lower than that of $48 \mathrm{mV}$ per decade for $\mathrm{CoSe}_{2}$ and $101 \mathrm{mV}$ per decade for 3D $\mathrm{MoS}_{2}$ aggregates (Table 1). This Tafel slope is also comparable to or 

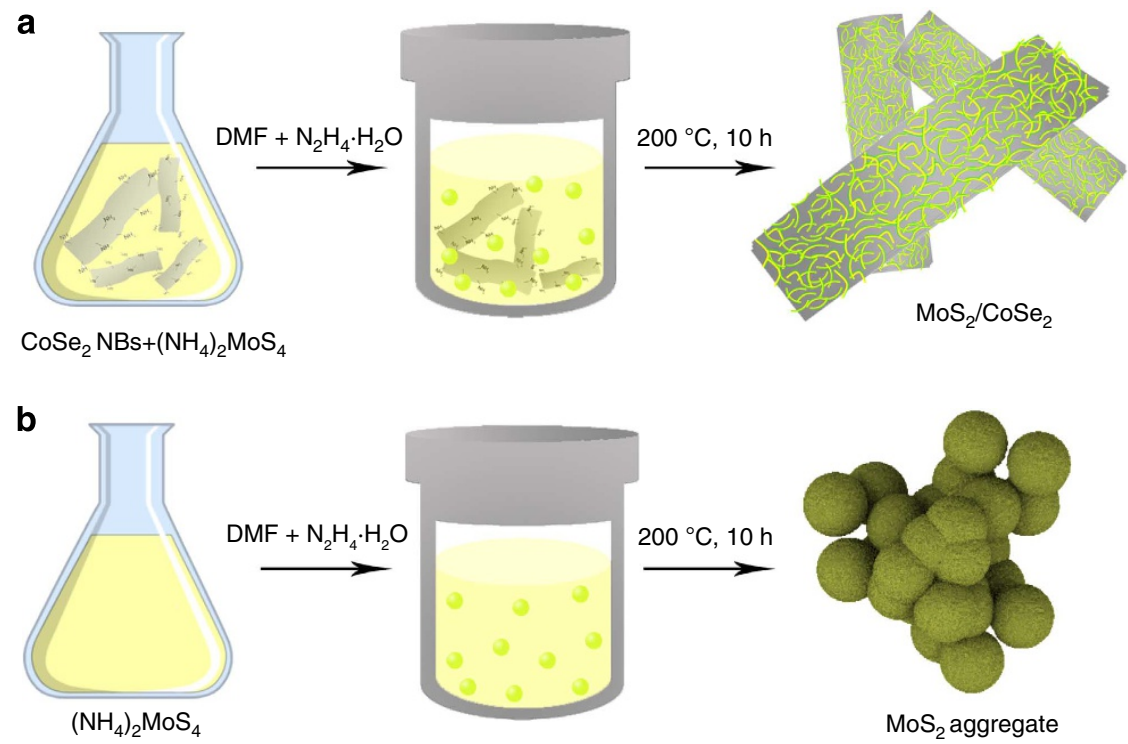

Figure 1 | Schematic illustration of the preparation of $\mathbf{M o S}_{\mathbf{2}} / \mathbf{C o S e}_{\mathbf{2}}$ hybrid. (a) Solvothermal synthesis with $\mathrm{CoSe}_{2} / \mathrm{DETA}$ nanobelts as substrates for preparation of $\mathrm{MoS}_{2} / \mathrm{CoSe}_{2}$ hybrid. (b) Solvothermal synthesis without $\mathrm{CoSe}_{2} / \mathrm{DETA}$ nanobelts leads to free $\mathrm{MoS}_{2}$ nanosheet aggregates.
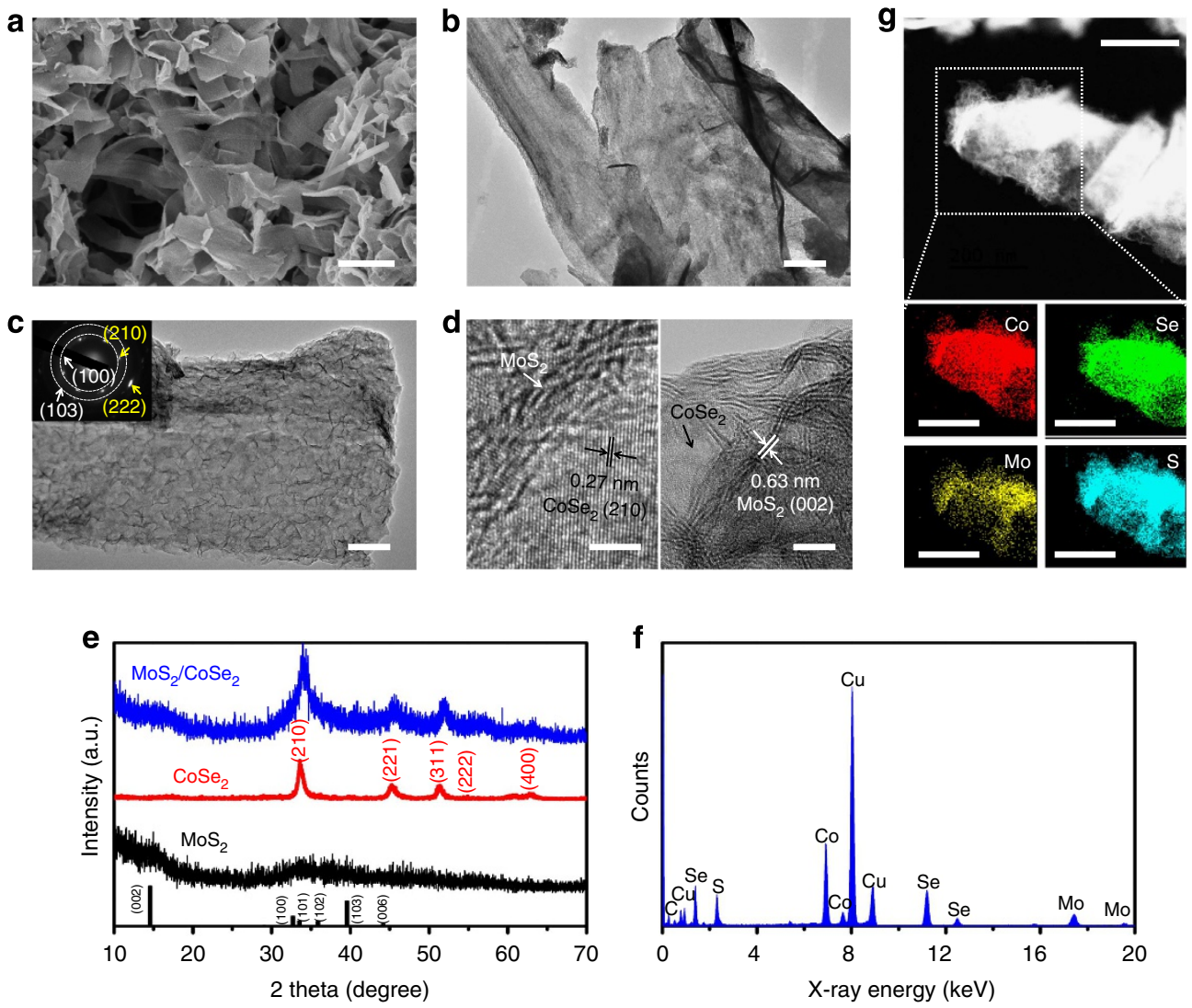

Figure 2 | Characterization of the $\mathbf{M o S}_{\mathbf{2}} / \mathrm{CoSe}_{\mathbf{2}}$ hybrid. (a) Scanning electron microscopy image of $\mathrm{MoS}_{2} / \mathrm{CoSe}_{2}$ hybrid. Scale bar, $800 \mathrm{~nm}$. (b,c) TEM images with different magnifications of $\mathrm{MoS}_{2} / \mathrm{CoSe}_{2}$ hybrid. Scale bars, 200 and $50 \mathrm{~nm}$, respectively. The inset in c shows corresponding SAED pattern. (d) HRTEM images of $\mathrm{MoS}_{2} / \mathrm{CoSe}_{2}$ hybrid showing distinguishable microstructures of $\mathrm{MoS}_{2}$ and $\mathrm{CoSe}_{2}$. Scale bars, $5 \mathrm{~nm}$. (e,f) XRD patterns and EDX spectrum of the $\mathrm{MoS}_{2} / \mathrm{CoSe}_{2}$ hybrid, respectively. (g) STEM-EDX elemental mapping of $\mathrm{MoS}_{2} / \mathrm{CoSe}_{2}$ hybrid showing clearly the homogeneous distribution of Co (red), Se (green), Mo (yellow) and S (azure). Scale bars, $200 \mathrm{~nm}$.

lower than that of all the reported noble-metal-free HER catalysts in the literature (Supplementary Table 1), demonstrating the superior HER kinetics of $\mathrm{MoS}_{2} / \mathrm{CoSe}_{2}$ hybrid. At high current densities (for example, $10 \mathrm{~mA} \mathrm{~cm}^{-2}$ with $\eta$ of $68 \mathrm{mV}$ ), $\mathrm{MoS}_{2} /$ $\mathrm{CoSe}_{2}$ hybrid also represents a more efficient catalyst relative to other noble-metal-free HER catalysts (Supplementary Table 1). The HER inherent activity of these catalysts was evaluated by the exchange current density $\left(j_{0}\right)$. The $j_{0}$ of $7.3 \times 10^{-2} \mathrm{~mA} \mathrm{~cm}^{-2}$ for $\mathrm{MoS}_{2} / \mathrm{CoSe}_{2}$ hybrid outperforms the values of $8.4 \times 10^{-3}$ $\mathrm{mA} \mathrm{cm}{ }^{-2}$ for pure $\mathrm{CoSe}_{2}$ and $9.1 \times 10^{-4} \mathrm{mAcm}^{-2}$ for pure 

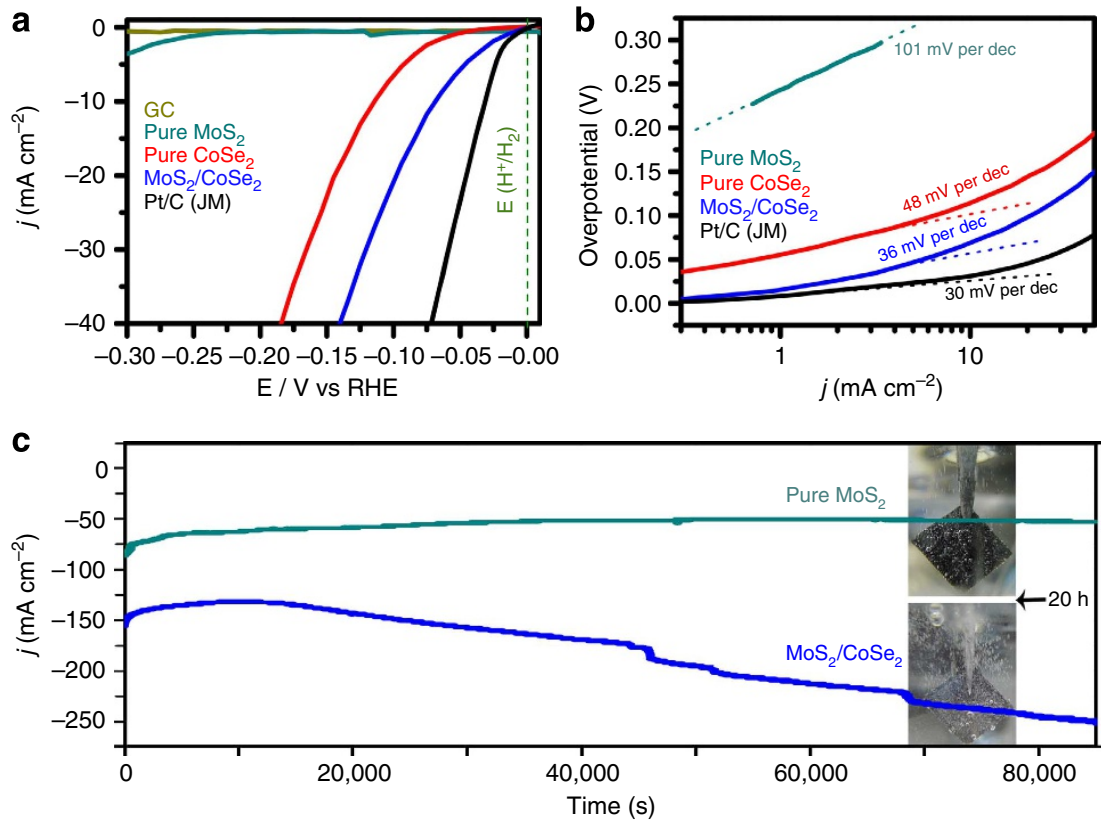

Figure 3 | Electrocatalytic hydrogen evolution of different catalysts. (a) Polarization curves for HER on bare GC electrode and modified GC electrodes comprising $\mathrm{MoS}_{2} / \mathrm{CoSe}_{2}$ hybrid, pure $\mathrm{MoS}_{2}$, pure $\mathrm{CoSe}_{2}$ and a high-quality commercial Pt/C catalyst. Catalyst loading is about $0.28 \mathrm{mg} \mathrm{cm}^{-2} \mathrm{for}$ all samples. Sweep rate: $2 \mathrm{mVs}^{-1}$. (b) Tafel plot for the various catalysts derived from a. (c) Chronoamperometric responses $(j \sim t)$ recorded on $\mathrm{MoS}_{2} / \mathrm{CoSe}_{2}$ hybrid and pure $\mathrm{MoS}_{2}$ at a constant applied potential of $-0.7 \mathrm{~V}$ vs SCE. The catalysts were deposited on CFP with the same loading of $1 \mathrm{mg} \mathrm{cm}^{-2}$. Inset digital photos show the $\mathrm{H}_{2}$ bubbles formed on $\mathrm{MoS}_{2}$-modified CFP (up) and $\mathrm{MoS}_{2} / \mathrm{CoSe}_{2}$-modified CFP (down) at the time point of $20 \mathrm{~h}$. All the measurements were performed in $\mathrm{H}_{2}$-saturated $0.5 \mathrm{M} \mathrm{H}_{2} \mathrm{SO}_{4}$ electrolyte. dec, decade.

\begin{tabular}{|c|c|c|c|}
\hline Catalyst & $\begin{array}{l}\text { Onset potention } \\
\text { (mV vs RHE) }\end{array}$ & $\begin{array}{c}\text { Tafel slope } \\
\text { ( } \mathrm{mV} \text { per decade) }\end{array}$ & $\begin{array}{c}\text { Exchange } \\
\text { current density } \\
\left(j_{0}, \mathrm{~mA} \mathrm{~cm}^{-2}\right)^{\star}\end{array}$ \\
\hline$\overline{\mathrm{MoS}_{2}}$ & -237 & 101 & $9.1 \times 10^{-4}$ \\
\hline $\mathrm{CoSe}_{2}$ & -50 & 48 & $8.4 \times 10^{-3}$ \\
\hline $\mathrm{MoS}_{2} / \mathrm{CoSe}_{2}$ & -11 & 36 & $7.3 \times 10^{-2}$ \\
\hline $\mathrm{Pt} / \mathrm{C}^{\dagger}$ & 0 & 30 & $7.1 \times 10^{-1}$ \\
\hline
\end{tabular}

$\mathrm{MoS}_{2}$ (Table 1) and also the $j_{0}$ value for most of the reported noble-metal-free HER catalysts (Supplementary Table 1). The high electrode kinetic metrics (including onset potential of $-11 \mathrm{mV}$ and the Tafel slope of $36 \mathrm{mV}$ per decade) and large $j_{0}$ (only $\sim 1$ order of magnitude lower than the value of $7.1 \times$ $10^{-1} \mathrm{~mA} \mathrm{~cm}^{-2}$ for $\mathrm{Pt}$ ) highlight the exceptional $\mathrm{H}_{2}$ evolving efficiency of the new $\mathrm{MoS}_{2} / \mathrm{CoSe}_{2}$ hybrid catalyst.

Material stability. The long-term stability of $\mathrm{MoS}_{2} / \mathrm{CoSe}_{2}$ hybrid catalyst was assayed by means of chronoamperometry measurement $(j \sim t)$ with a high catalyst loading of $1 \mathrm{mg} \mathrm{cm}^{-2}$ on carbon fibre paper (CFP). This quasi-electrolysis process was performed at a constant potential of $-0.7 \mathrm{~V}$ vs SCE in $0.5 \mathrm{M} \mathrm{H}_{2} \mathrm{SO}_{4}$ for $24 \mathrm{~h}$. As shown in Fig. 3c, the current density of $\mathrm{MoS}_{2} / \mathrm{CoSe}_{2}$-modified CFP electrode decreased gradually at the initial $3 \mathrm{~h}$, which then increased quickly over $24 \mathrm{~h}$ of continuous operation. We hypothesize that the more efficient HER-active sites in our hybrid materials are the interfaces between $\mathrm{MoS}_{2}$ and $\mathrm{CoSe}_{2}$, where Co from the support materials could promote the HER kinetics by

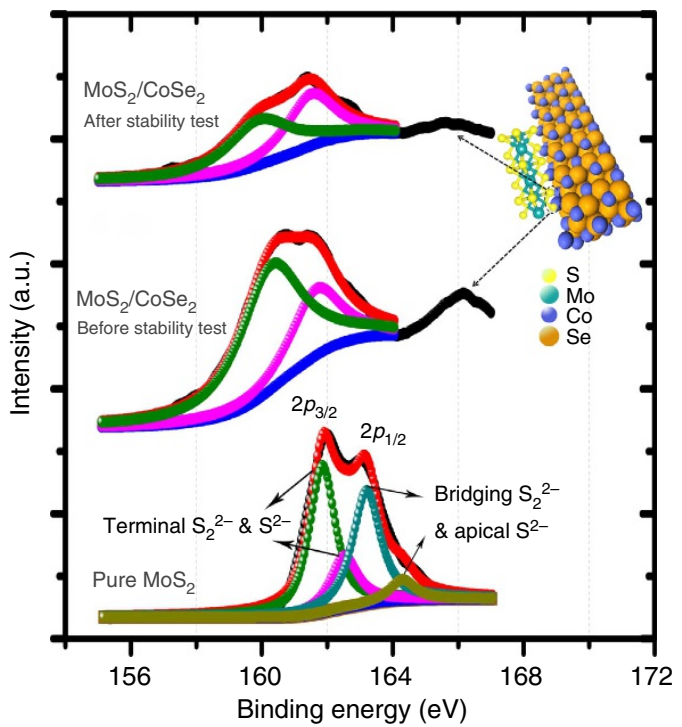

Figure 4 | S 2p XPS spectrum analysis. S $2 p$ XPS spectra for pure $\mathrm{MoS}_{2}$, $\mathrm{MoS}_{2} / \mathrm{CoSe}_{2}$ hybrid and $\mathrm{MoS}_{2} / \mathrm{CoSe}_{2}$ hybrid after stability test. The top right corner demonstrates the structure model of $\mathrm{MoS}_{2} / \mathrm{CoSe}_{2}$ hybrid.

lowering the Gibbs free energy of adsorbed hydrogen $\left(\Delta G_{\mathrm{H}}\right)^{8,29,30}$. The severe reducing condition at the initial $3 \mathrm{~h}$ caused degradation of external $\mathrm{MoS}_{2}$ and allowed more electrolyte to access the $\mathrm{MoS}_{2}-\mathrm{CoSe}_{2}$ interfaces (Supplementary Fig. 11; Supplementary Note 1; Supplementary Table 2), yielding the increased HER current density. Remarkably, after $24 \mathrm{~h}$ of operation, XPS studies revealed no obvious chemical state change of HER-active S (Fig. 4) and the homogeneous elemental distribution was maintained (Supplementary Fig. 12; Supplementary Note 1), suggesting the robustness of the hybrid 


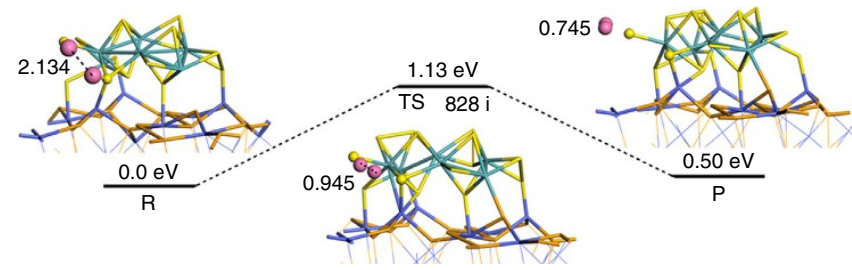

Figure 5 | HER mechanism. Reaction pathway of $\mathrm{HER}$ on $\mathrm{MoS}_{2} / \mathrm{CoSe}_{2}$ hybrid according to the Volmer-Tafel route. The calculated distance of two hydrogen atoms and energies are displayed in $\AA$ and eV. Blue, orange, azure, yellow and pink indicate $\mathrm{Co}, \mathrm{Se}, \mathrm{Mo}, \mathrm{S}$ and $\mathrm{H}$ atoms, respectively.

catalyst. By comparison, under the exact same condition, the pure $\mathrm{MoS}_{2}$ catalyst exhibited a slow but continuous decrease in HER activity. Furthermore, digital photo (inset in Fig. 3c) taken from $\mathrm{MoS}_{2} / \mathrm{CoSe}_{2}$-modified CFP electrode showed vigorous effervescence at $20 \mathrm{~h}$ (also Supplementary Movie 1), comparing favourably with the $\mathrm{H}_{2}$ bubbles formed on free $\mathrm{MoS}_{2}$-modified electrode. The exceptional long-term durability of our $\mathrm{MoS}_{2} /$ $\mathrm{CoSe}_{2}$ hybrid catalyst suggests the promise for implementing this new catalyst into realistic hydrogen evolution electrode.

HER-enhanced mechanism. The experimentally observed high HER intrinsic activity $\left(j_{0}=7.3 \times 10^{-2} \mathrm{mAcm}^{-2}\right)$ of $\mathrm{MoS}_{2} /$ $\mathrm{CoSe}_{2}$ hybrid catalyst prompted us to probe the enhanced mechanism. Generally, the value of $\Delta G_{\mathrm{H}}$ is considered as a reasonable descriptor of HER activity for a wide variety of catalysts $^{3,30,31}$. An optimum HER activity is suggested to be achieved at value of $\Delta G_{\mathrm{H}} \approx 0$ (ref. 30). Lower $\Delta G_{\mathrm{H}}$ will lead to very high surface coverage of $H_{\mathrm{ads}}$, while higher $\Delta G_{\mathrm{H}}$ will make the protons bonded too weakly on the catalyst surface, which both lead to the slow HER kinetics ${ }^{3,30,31}$. Previous density functional theory (DFT) calculations ${ }^{5}$ showed that $\mathrm{MoS}_{2}$ edge sites with unsaturated sulfur atoms can lower the $\Delta G_{\mathrm{H}}$ approaching to 0 and thus are active for HER, which was later proved by Jaramillo et al. ${ }^{6}$ experimentally. Recently, $\mathrm{Hu}$ and coworkers ${ }^{13,14}$ found that amorphous $\mathrm{MoS}_{2}$ films are particularly HER active and the increased coordinately and structurally unsaturated sulfur atoms led to the enhancement. Furthermore, first-row transition metal ions, especially $\mathrm{Co}$, can promote the HER activity of $\mathrm{MoS}_{2}$ by coupling with S-edges to lower their $\Delta G_{\mathrm{H}}$ from 0.18 to $0.10 \mathrm{eV}$ to afford a faster proton adsorption kinetics $8,29,30$. As to $\mathrm{MoS}_{2} / \mathrm{CoSe}_{2}$ hybrid catalyst, the quasiamorphous $\mathrm{MoS}_{2}$ around the $\mathrm{CoSe}_{2}$ may bring in more active edge sites. Meanwhile, the $\mathrm{CoSe}_{2}$ chemically interacts with $\mathrm{MoS}_{2}$ by forming S-Co bond (Fig. 4 and inset), similar to the XPS peak observed in Co-promoted $\mathrm{MoS}_{3}$ film ${ }^{32}$, which can further improve the HER activity of $\mathrm{MoS}_{2}$. By contrast, no such XPS peak was found in Fig. 4 for pure $\mathrm{MoS}_{2}$ catalyst. XPS analyses of the $\mathrm{S} 2 p$ region also exhibit a dramatically decreased electronbinding energy (by $\sim 1.3 \mathrm{eV}$ ) after growing $\mathrm{MoS}_{2}$ on the $\mathrm{CoSe}_{2}$, suggesting the formation of more terminal $\mathrm{S}_{2}^{2-}$ and $\mathrm{S}^{2-}$ ions, which are HER active (Fig. 4) ${ }^{14,19}$. Therefore, the $\mathrm{CoSe}_{2}$ nanobelts, a material with decent HER activity by itself, can not only chemically couple with $\mathrm{MoS}_{2}$ to promote the HER activity, but also serve as an effective support for mediating the growth of $\mathrm{MoS}_{2}$ to form more terminal $\mathrm{S}_{2}^{2-}$ and $\mathrm{S}^{2-}$. Meanwhile, anchored $\mathrm{MoS}_{2}$ may also boost the HER-active sites of $\mathrm{CoSe}_{2}$ and these electrocatalytic synergistic effects ${ }^{33}$ together lead to the high HER performance of $\mathrm{MoS}_{2} / \mathrm{CoSe}_{2}$ hybrid catalyst.

For the HER in acidic media, two separate pathways (the Volmer-Tafel or the Volmer-Heyrovsky mechanism) have been proposed for reducing $\mathrm{H}^{+}$to $\mathrm{H}_{2}$ (refs 30,34). Specifically, the two distinct mechanisms involve three principal steps, referring to the
Volmer (electrochemical hydrogen adsorption: $\mathrm{H}_{3} \mathrm{O}^{+}+\mathrm{e}^{-} \rightarrow$ $\mathrm{H}_{\text {ads }}+\mathrm{H}_{2} \mathrm{O}$ ), the Heyrovsky (electrochemical desorption: $\mathrm{H}_{\text {ads }}+\mathrm{H}_{3} \mathrm{O}^{+}+\mathrm{e}^{-} \rightarrow \mathrm{H}_{2}+\mathrm{H}_{2} \mathrm{O}$ ) and the Tafel (chemical desorption: $\mathrm{H}_{\text {ads }}+\mathrm{H}_{\mathrm{ads}} \rightarrow \mathrm{H}_{2}^{\uparrow}$ ) reactions ${ }^{30,34}$. Tafel slope, an intrinsic property of electrocatalysts, could be used to probe the elementary steps involved in the $\mathrm{H}_{2}$ evolution. For example, HER kinetic models suggest that Tafel slope of about 120,40 or $30 \mathrm{mV}$ per decade will be obtained if the Volmer, Heyrovsky or Tafel reaction is the rate-determining step, respectively ${ }^{34}$. The Tafel slope down to $\sim 36 \mathrm{mV}$ per decade for $\mathrm{MoS}_{2} / \mathrm{CoSe}_{2}$ in $0.5 \mathrm{M}$ $\mathrm{H}_{2} \mathrm{SO}_{4}$ is the lowest value measured till now for $\mathrm{MoS}_{2}$-based HER catalysts (Supplementary Table 1), even approaching to that of $\sim 30 \mathrm{mV}$ per decade for $\mathrm{Pt} / \mathrm{C}$ catalysts. This Tafel slope suggests a Tafel-step-determined Volmer-Tafel mechanism works in the $\mathrm{MoS}_{2} / \mathrm{CoSe}_{2}$ catalyst, where the synergistic CoSe $\mathrm{C}_{2}$ substrate with decent HER activity presumably contributes to this HER mechanism.

Considering that at least one decade of linearity in Tafel extrapolation at relatively large $\eta$ is desirable to ensure an accurate Tafel analysis, the calculated Tafel slopes (Fig. 3b) and derived HER mechanism may be inconclusive. To prove the proposed HER mechanism, we performed a computational study on the new $\mathrm{MoS}_{2} / \mathrm{CoSe}_{2}$ catalyst to gain detailed insights into the adsorption, activation and reaction processes (Fig. 5; see Supplementary Methods for computational details). DFT calculations suggested that reactant $(\mathbf{R})$ contains two $\mathrm{H}$ atoms adsorbed on different sites of the optimized $\mathrm{MoS}_{2} / \mathrm{CoSe}_{2}$ model with $\mathrm{H}-\mathrm{H}$ distance of $2.134 \AA$. Two approached $\mathrm{H}$ atoms on the side $\mathrm{S}$ atoms of $\mathrm{MoS}_{2}$ cluster then formed a transition state (TS) with $\mathrm{H}-\mathrm{H}$ distance of $0.945 \AA$ and imaginary vibration frequency of $828 i \mathrm{~cm}^{-1}$. After crossing the TS, product $(\mathbf{P})$ with a weakly absorbed $\mathrm{H}_{2}$ molecule $(0.745 \AA)$ was formed. The calculated activation barrier of $1.13 \mathrm{eV}\left(30.7 \mathrm{kcal} \mathrm{mol}^{-1}\right)$ for the Tafel-step reaction on $\mathrm{MoS}_{2} / \mathrm{CoSe}_{2}$ hybrid, which can be overcome at a slightly higher $\eta$, approaches that of Pt (111) electrode ${ }^{35}$, agreeing well with our experimentally observed fast HER kinetics.

\section{Discussion}

In conclusion, we demonstrate that an effective and robust hydrogen evolution catalyst can be made by marrying inexpensive transition metal chalcogenides. The new $\mathrm{MoS}_{2} / \mathrm{CoSe}_{2}$ catalyst shows exceptional HER catalytic properties in acidic electrolyte with onset potential of mere $-11 \mathrm{mV}$, a small Tafel slope of $36 \mathrm{mV}$ per decade and a high exchange current density, representing the first non-noble metal catalyst that approaches the performance of state-of-the-art $\mathrm{Pt} / \mathrm{C}$ catalyst. Inspired by the Nature using transition metals as catalytically active site to construct effective HER catalysts (for example, hydrogenase enzymes $)^{5,36}$, we believe that our study here will facilitate the development of newly efficient HER catalysts based on transitional metal chalcogenides.

\section{Methods}

Synthesis of $\mathrm{CoSe}_{2} / \mathrm{DETA}$ nanobelts and $\mathrm{MoS}_{2} / \mathrm{CoSe}_{2}$ hybrid. All chemicals are of analytical grade and were used as received without further purification. First, ultrathin lamellar mesostructured $\mathrm{CoSe}_{2} / \mathrm{DETA}$ nanobelts were prepared by our

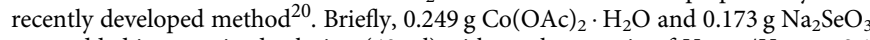
were added into a mixed solution $(40 \mathrm{ml})$ with a volume ratio of $V_{\text {DETA }} / V_{\text {DIW }}=2: 1$ (DIW, deionized water). The obtained wine solution was then transferred into a $50 \mathrm{ml}$ Taflon-lined autoclave, which was sealed and maintained at $180^{\circ} \mathrm{C}$ for $16 \mathrm{~h}$. The resulting black floccules were collected by centrifugation $(4,000$ r.p.m. for $5 \mathrm{~min}$ ) and washed by absolute ethanol for three times, and the resulting $\mathrm{CoSe}_{2} /$ DETA nanobelts were dried for next use. To prepare the $\mathrm{MoS}_{2} / \mathrm{CoSe}_{2}$ hybrid, $10 \mathrm{mg}$ freshly made CoSe 2 /DETA nanobelts and $10 \mathrm{mg}\left(\mathrm{NH}_{4}\right)_{2} \mathrm{MoS}_{4}$ were dispersed in $10 \mathrm{ml} \mathrm{DMF}$ and sonicated for $15 \mathrm{~min}$ under ambient conditions. Then, $0.05 \mathrm{ml}$ $\mathrm{N}_{2} \mathrm{H}_{4} \cdot \mathrm{H}_{2} \mathrm{O}$ was added into the suspension. After sonicating for another $15 \mathrm{~min}$ to dissolve completely, the mixed solution was transferred into a $50 \mathrm{ml}$ Teflon-lined autoclave, which was sealed and heated in an oven at $200^{\circ} \mathrm{C}$ for $10 \mathrm{~h}$ and then 
cooled to room temperature naturally. The resulting black product was collected by centrifugation (7,000 r.p.m. for $8 \mathrm{~min})$, then washed at least four times by distilled water and absolute ethanol to remove ions and possible remnants, and dried under vacuum at $80^{\circ} \mathrm{C}$ for $6 \mathrm{~h}$.

Synthesis of free 3D $\mathbf{M o S}_{\mathbf{2}}$ sheet aggregates. The synthetic procedure of free $3 \mathrm{D} \mathrm{MoS}$ sheet aggregates is the same with that for preparing $\mathrm{MoS}_{2} / \mathrm{CoSe}_{2}$ hybrid, the only difference is that no $\mathrm{CoSe}_{2} / \mathrm{DETA}$ nanobelt substrates were added during the synthesis.

Characterization. The samples were characterized by different analytic techniques. X-ray powder diffraction (XRD) was carried out on a Rigaku D/max-rA $\mathrm{X}$-ray diffractometer with $\mathrm{Cu}$ Ka radiation $(\lambda=1.54178 \AA)$; TEM images, HRTEM images, SAED and an energy-disperse X-ray spectrum (EDS) were taken with a JEOJ-2010 transmission electron microscope with an acceleration voltage of $200 \mathrm{kV}$. STEM and EDX elemental mapping were performed on JEOL ARM-200F. The X-ray photoelectron spectra (XPS) were recorded on an ESCALab MKII XPS using $\mathrm{Mg}$ Ka radiation exciting source. The Fourier transform infrared spectra were measured on a Bruker Vector-22 FT-IR spectrometer at room temperature. Nitrogen sorption was determined by Brunauer, Emmett and Teller measurements with an ASAP-2020 surface area analyzer (see Supplementary Fig. 8 for results). The degradation of external $\mathrm{MoS}_{2}$ around $\mathrm{CoSe}_{2}$ was determined by the inductively coupled plasma-atomic emission spectrometry analysis using an Atomscan Advantage (Thermo Ash Jarrell Corporation, USA) spectrometer.

Electrocatalytic study. Electrochemical measurements were performed at room temperature using a rotating disk working electrode made of GC (PINE, $5 \mathrm{~mm}$ diameter, $0.196 \mathrm{~cm}^{2}$ ) connected to a Multipotentiostat (IM6ex, ZAHNER elektrik, Germany). The GC electrode was polished to a mirror finish (No. 40-6365-006, Gamma Micropolish Alumina, Buehler; No.40-7212, Microcloth, Buehler) and thoroughly cleaned before use. Pt wire and SCE were used as counter and reference electrodes, respectively. The potentials reported in our work were vs the RHE through RHE calibration described below.

The preparation method of the working electrodes containing investigated catalysts can be found as follows. In short, $5 \mathrm{mg}$ of catalyst powder was dispersed in $1 \mathrm{ml}$ of 3:1 v/v DIW/isopropanol mixed solvent with $40 \mu \mathrm{l}$ of Nafion solution ( $5 \mathrm{wt} \%$, Sigma-Aldrich), then the mixture was ultrasonicated for about $30 \mathrm{~min}$ to generate a homogeneous ink. Next, $10 \mu \mathrm{l}$ of the dispersion was transferred onto the GC disk, leading to the catalyst loading $\sim 0.28 \mathrm{mg} \mathrm{cm}^{-2}$. Finally, the as-prepared catalyst film was dried at room temperature. For comparison, bare GC electrode that has been polished and cleaned was also dried for electrochemical measurement.

Before the electrochemical measurement, the electrolyte $\left(0.5 \mathrm{M} \mathrm{H}_{2} \mathrm{SO}_{4}\right)$ was degassed by bubbling pure hydrogen for at least 30 min to ensure the $\mathrm{H}_{2} \mathrm{O} / \mathrm{H}_{2}$ equilibrium at $0 \mathrm{~V}$ vs RHE at a rotation rate of 1,600 r.p.m. The polarization curves were obtained by sweeping the potential from -0.7 to $-0.2 \mathrm{~V}$ vs SCE at room temperature and 1,600 r.p.m. (to remove the in situ-formed $\mathrm{H}_{2}$ bubbles on the $\mathrm{RDE}$ ), with a sweep rate of $2 \mathrm{mV} \mathrm{s}^{-1}$. The electrochemical impedance spectroscopy measurement was performed in the same configuration at open circuit potential over a frequency range from $100 \mathrm{kHz}$ to $5 \mathrm{mHz}$ at the amplitude of the sinusoidal voltage of $5 \mathrm{mV}$ and room temperature (see Supplementary Fig. 10 for results). $\mathrm{MoS}_{2} / \mathrm{CoSe}_{2}$ and pure $\mathrm{MoS}_{2}$-coated CFPs (Toray, $1 \mathrm{~cm}^{2}$, catalyst loading $1 \mathrm{mg}$ ) were used as working electrodes to collect chronoamperometry data at the applied potential of $-0.7 \mathrm{~V}$ vs SCE. The polarization curves were replotted as overpotential $(\eta)$ vs $\log$ current $(\log j)$ to get Tafel plots for assessing the HER kinetics of investigated catalysts. By fitting the linear portion of the Tafel plots to the Tafel equation $(\eta=b \log (j)+a)$, the Tafel slope $(b)$ can be obtained. All data were reported without iR compensation.

RHE calibration. In all measurements, we used SCE as the reference electrode. It was calibrated with respect to RHE. The calibration was performed in the high-purity hydrogen-saturated electrolyte with a Pt foil as the working electrode. Cyclic voltammetry was run at a scan rate of $1 \mathrm{mV} \mathrm{s}^{-1}$, and the average of the two potentials at which the current crossed 0 was taken to be the thermodynamic potential for the hydrogen electrode reaction. In $0.5 \mathrm{M} \mathrm{H}_{2} \mathrm{SO}_{4}$ solution, $E_{\mathrm{RHE}}=E_{\mathrm{SCE}}+0.28 \mathrm{~V}$.

DFT calculations. The computational modelling of the adsorption, activation and reaction processes involved in HER on $\mathrm{MoS}_{2} / \mathrm{CoSe}_{2}$ was performed by periodic DFT with the Vienna Ab-initio Simulation Package (VASP). $\mathrm{MoS}_{2} / \mathrm{CoSe}_{2}$ modelbuilding details (Supplementary Figs 13-15), HER mechanism and relevant references are provided in the Supplementary Methods.

\section{References}

1. Walter, M. G. et al. Solar water splitting cells. Chem. Rev. 110, 6446-6473 (2010).

2. Cook, T. R. et al. Solar energy supply and storage for the legacy and nonlegacy worlds. Chem. Rev. 110, 6474-6502 (2010).
3. Greeley, J., Jaramillo, T. F., Bonde, J., Chorkendorff, I. B. \& Norskov, J. K. Computational high-throughput screening of electrocatalytic materials for hydrogen evolution. Nat. Mater. 5, 909-913 (2006).

4. Prins, R., Debeer, V. H. J. \& Somorjai, G. A. Structure and function of the catalyst and the promoter in Co-Mo hydrodesulfurization catalysts. Catal. Rev. Sci. Eng. 31, 1-41 (1989).

5. Hinnemann, B. et al. Biornimetic hydrogen evolution: $\mathrm{MoS}_{2}$ nanoparticles as catalyst for hydrogen evolution. J. Am. Chem. Soc. 127, 5308-5309 (2005).

6. Jaramillo, T. F. et al. Identification of active edge sites for electrochemical $\mathrm{H}_{2}$ evolution from $\mathrm{MoS}_{2}$ nanocatalysts. Science 317, 100-102 (2007).

7. Karunadasa, H. I. et al. A molecular $\mathrm{MoS}_{2}$ edge site mimic for catalytic hydrogen generation. Science 335, 698-702 (2012).

8. Bonde, J., Moses, P. G., Jaramillo, T. F., Norskov, J. K. \& Chorkendorff, I. Hydrogen evolution on nano-particulate transition metal sulfides. Faraday Discuss. 140, 219-231 (2008).

9. Kibsgaard, J., Chen, Z. B., Reinecke, B. N. \& Jaramillo, T. F. Engineering the surface structure of $\mathrm{MoS}_{2}$ to preferentially expose active edge sites for electrocatalysis. Nat. Mater. 11, 963-969 (2012).

10. Lukowski, M. A. et al. Enhanced hydrogen evolution catalysis from chemically exfoliated metallic $\mathrm{MoS}_{2}$ nanosheets. J. Am. Chem. Soc. 135, 10274-10277 (2013).

11. Kong, D. S. et al. Synthesis of $\mathrm{MoS}_{2}$ and $\mathrm{MoSe}_{2}$ films with vertically aligned layers. Nano Lett. 13, 1341-1347 (2013).

12. Xie, J. F. et al. Defect-rich $\mathrm{MoS}_{2}$ ultrathin nanosheets with additional active edge sites for enhanced electrocatalytic hydrogen evolution. Adv. Mater. 25, 5807-5813 (2013).

13. Merki, D., Fierro, S., Vrubel, H. \& Hu, X. L. Amorphous molybdenum sulfide films as catalysts for electrochemical hydrogen production in water. Chem. Sci. 2, 1262-1267 (2011).

14. Vrubel, H., Merki, D. \& Hu, X. L. Hydrogen evolution catalyzed by $\mathrm{MoS}_{3}$ and $\mathrm{MoS}_{2}$ particles. Energy Environ. Sci. 5, 6136-6144 (2012).

15. Benck, J. D., Chen, Z. B., Kuritzky, L. Y., Forman, A. J. \& Jaramillo, T. F. Amorphous molybdenum sulfide catalysts for electrochemical hydrogen production: insights into the origin of their catalytic activity. ACS Catal. 2, 1916-1923 (2012).

16. Liao, L. et al. $\mathrm{MoS}_{2}$ formed on mesoporous graphene as a highly active catalyst for hydrogen evolution. Adv. Funct. Mater. 23, 5326-5333 (2013).

17. Li, Y. G. et al. $\mathrm{MoS}_{2}$ nanoparticles grown on graphene: an advanced catalyst for the hydrogen evolution reaction. J. Am. Chem. Soc. 133, 7296-7299 (2011).

18. Chen, Z. B. et al. Core-shell $\mathrm{MoO}_{3}-\mathrm{MoS}_{2}$ nanowires for hydrogen evolution: a functional design for electrocatalytic materials. Nano Lett. 11, 4168-4175 (2011).

19. Wang, T. Y. et al. Enhanced electrocatalytic activity for hydrogen evolution reaction from self-assembled monodispersed molybdenum sulfide nanoparticles on an Au electrode. Energy Environ. Sci. 6, 625-633 (2013).

20. Gao, M. R., Yao, W. T., Yao, H. B. \& Yu, S. H. Synthesis of unique ultrathin lamellar mesostructured $\mathrm{CoSe}_{2}$-amine (protonated) nanobelts in a binary solution. J. Am. Chem. Soc. 131, 7486-7487 (2009).

21. Gao, M. R., Xu, Y. F., Jiang, J., Zheng, Y. R. \& Yu, S. H. Water oxidation electrocatalyzed by an efficient $\mathrm{Mn}_{3} \mathrm{O}_{4} / \mathrm{CoSe}_{2}$ nanocomposite. J. Am. Chem. Soc. 134, 2930-2933 (2012).

22. Gao, M. R. et al. A methanol-tolerant $\mathrm{Pt} / \mathrm{CoSe}_{2}$ nanobelt cathode catalyst for direct methanol fuel cells. Angew. Chem. Int. Ed. 50, 4905-4908 (2011).

23. Gao, M. R. et al. In situ controllable synthesis of magnetite nanocrystals/CoSe hybrid nanobelts and their enhanced catalytic performance. J. Mater. Chem. 20, 9355-9361 (2010).

24. Gao, M. R. et al. Mixed-solution synthesis of sea urchin-like NiSe nanofiber assemblies as economical Pt-free catalysts for electrochemical $\mathrm{H}_{2}$ production. J. Mater. Chem. 22, 13662-13668 (2012).

25. Xu, Y. F., Gao, M. R., Zheng, Y. R., Jiang, J. \& Yu, S. H. Nickel/nickel(II) oxide nanoparticles anchored onto cobalt(IV) diselenide nanobelts for the electrochemical production of hydrogen. Angew. Chem. Int. Ed. 52, 8546-8550 (2013).

26. Gao, M. R., Jiang, J. \& Yu, S. H. Solution-based synthesis and design of late transition metal chalcogenide materials for oxygen reduction reaction (ORR). Small 8, 13-27 (2012).

27. Gao, M. R., Xu, Y. F., Jiang, J. \& Yu, S. H. Nanostructured metal chalcogenides: synthesis, modification, and applications in energy conversion and storage devices. Chem. Soc. Rev. 42, 2986-3017 (2013).

28. Kong, D. S., Cha, J. J., Wang, H. T., Lee, H. R. \& Cui, Y. First-row transition metal dichalcogenide catalysts for hydrogen evolution reaction. Energy Environ. Sci. 6, 3553-3558 (2013).

29. Merki, D. \& Hu, X. L. Recent developments of molybdenum and tungsten sulfides as hydrogen evolution catalysts. Energy Environ. Sci. 4, 3878-3888 (2011).

30. Parasons, R. The rate of electrolytic hydrogen evolution and the heat of adsorption of hydrogen. Trans. Faraday Soc. 54, 1053-1063 (1958) 
31. Norskov, J. K. et al. Trends in the exchange current for hydrogen evolution. J. Electrochem. Soc. 152, J23-J26 (2005).

32. Merki, D., Vrubel, H., Rovelli, L., Fierro, S. \& Hu, X. L. Fe, Co, and Ni ions promote the catalytic activity of amorphous molybdenum sulfide films for hydrogen evolution. Chem. Sci. 3, 2515-2525 (2012).

33. Chen, W. F. et al. Hydrogen-evolution catalysts based on non-noble metal nickel-molybdenum nitride nanosheets. Angew. Chem. Int. Ed. 51, 6131-6135 (2012).

34. Conway, B. E. \& Tilak, B. V. Interfacial processes involving electrocatalytic evolution and oxidation of $\mathrm{H}_{2}$, and the role of chemisorbed H. Electrochim. Acta 47, 3571-3594 (2002).

35. Skulason, E. et al. Modeling the electrochemical hydrogen oxidation and evolution reactions on the basis of density functional theory calculations. J. Phys. Chem. C 114, 18182-18197 (2010).

36. DuBois, M. R. \& DuBois, D. L. The roles of the first and second coordination spheres in the design of molecular catalysts for $\mathrm{H}_{2}$ production and oxidation. Chem. Soc. Rev. 38, 62-72 (2009).

\section{Acknowledgements}

We acknowledge the funding support from the National Basic Research Program of China (Grants 2010CB934700, 2013CB933900, 2014CB931800 and 2013CB834603), the National Natural Science Foundation of China (Grants 21431006, 91022032, 91227103, 21061160492 and J1030412) and the Chinese Academy of Sciences (Grant KJZD-EW-M01-1).

\section{Author contributions}

S.-H.Y. and M.-R.G. conceived the idea. M.-R.G., Y.-R.Z. and Y.-F.X. planned and performed the experiments, collected and analysed the data. J.-X.L. and J.L. performed the DFT calculations. J.J. and Q.G. assisted with the experiments and characterizations. M.-R.G. and S.-H.Y. co-wrote the manuscript. All authors discussed the results and commented on the manuscript.

\section{Additional information}

Supplementary Information accompanies this paper at http://www.nature.com/ naturecommunications

Competing financial interests: The authors declare no competing financial interests

Reprints and permission information is available online at http://npg.nature.com/ reprintsandpermissions/

How to cite this article: Gao, M.-R. et al. An efficient molybdenum disulfide/cobalt diselenide hybrid catalyst for electrochemical hydrogen generation. Nat. Commun. 6:5982 doi: 10.1038/ncomms6982 (2015).

(c) (i) This work is licensed under a Creative Commons Attribution 4.0 International License. The images or other third party material in this article are included in the article's Creative Commons license, unless indicated otherwise in the credit line; if the material is not included under the Creative Commons license, users will need to obtain permission from the license holder to reproduce the material. To view a copy of this license, visit http://creativecommons.org/licenses/by/4.0/ 